\title{
Período Romântico Brasileiro: Alguns Aspectos da Produção Camerística*
}

\author{
Maria Alice Volpe
}

\section{Introdução}

O século XIX foi um período importante no desenvolvimento da música no Brasil. Até então fomentada muito especialmente pela Igreja, a música conquistou, a partir daí, novos ambientes de cultivo. Desenvolveu-se toda uma rede de atividades correlacionadas à presença da música na vida urbana: o ensino, os clubes musicais, os teatros, as salas de concerto, os periódicos especializados, a crítica musical, as obras teóricas, o movimento editorial e a importação e fabricação de instrumentos musicais. Esse processo de secularização da música no Brasil, que se iniciou com a ópera, dentre outros gêneros, manifestou-se também na música instrumental a partir da segunda metade do século. Nesse campo, a música para piano solo e sinfônica recebeu maior atenção nos compêndios posteriores de história da música brasileira. A escassez de informações e comentários sobre a música de câmara de autores românticos brasileiros induziu à impressão de que tal produção tivesse sido igualmente escassa. Não podemos irreverentemente desvalorizar a bibliografia que até agora enfocou o período (Renato Almeida,

\footnotetext{
* Este trabalho é um resumo parcial da dissertação de Mestrado em Musicologia, apresentada pela autora à UNESP - São Paulo, sob orientação do prof. Dr. Régis Duprat.
} 
Vincenzo Cernicchiaro, Isa Queirós Santos, Luís Heitor, Vasco Mariz, Enciclopédia da Música Brasileira e outros). Entretanto, tal problema foi abordado de forma não sistematizada e uma série de lacunas, imprecisões e até mesmo discordância de informações têm dificultado o acesso a esse conjunto de obras. Chama a atenção a inexistência de uma obra de caráter referencial que o assunto demanda. Parece ter predominado, ainda, certa negligência num passado recente, no que diz respeito à preservação, reprodução, editoração e execução desse repertório. Grande parte dessa documentação musical tem permanecido inédita e esquecida nos arquivos, bibliotecas e coleções particulares, à deriva do tempo e até em condições insuficientes de conservação.

Tratando-se, portanto, de assunto amplo e inexplorado, propusemo-nos à elaboração de um trabalho de caráter referencial, que oferecesse elementos para a identificação e localização de obras do período. O projeto que desenvolvemos consiste num estudo sistemático da produção camerística romântica brasileira e a elaboração de um catálogo das obras arroladas. O período romântico foi escolhido por representar o primeiro momento significativo desse gênero de composição no Brasil.

Antes de adentrarmos o assunto, cabe esclarecer alguns parâmetros básicos que guiaram a nossa pesquisa. Inicialmente, definir o que classificamos como música de câmara. Na definição do contingente instrumental abordado, optamos por uma classificação geral de duos a octetos, excluindo a música para instrumento solista, para piano a quatro mãos ou dois pianos, e a canção de câmara. Consideramos que tais agrupamentos necessitariam de trabalho específico, dada uma previsível quantidade considerável de títulos que envolveria.

A pesquisa abrangeu o período de 1850 a 1930 , incluindo a produção de compositores nascidos entre 1834 (ano de nascimento de Santana Gomes) e 1884 (ano de nascimento de Glauco Velasquez). Em tal conjunto foram incorporados compositores estrangeiros radicados no Brasil, pela importância.que tiveram para a vida musical do período. É preciso salientar que, não obstante ter- 
mos estabelecido o ano de nascimento de Santana Gomes como referencial inicial para os compositores que seriam incluídos no trabalho, e o ano de nascimento de Glauco Velasquez como referencial final, foi necessário atribuir certa flexibilidade a tais marcos cronológicos. Por exemplo, alguns compositores nascidos antes de 1884 foram excluídos do conjunto de autores que compõem o nosso trabalho, por terem-se destacado sobretudo no período subseqüente, o Modernismo. Outro fato é termos estendido o período romântico musical brasileiro além da década de 1920 . Embora a Semana de Arte Moderna de 1922 represente um divisor de águas entre Romantismo e Modernismo, temos que levar em consideração que o romantismo musical brasileiro se estendeu pelo menos por uma década após o advento do modernismo no Brasil. Não caberia excluir a produção de autores românticos que sobreviveram à eclosão do movimento, como, por exemplo, Henrique Oswald, falecido em 1931; João Gomes Araújo, nascido em 1846 e desaparecido em 1943; ou ainda Paulo Florence, autor paulista nascido no mesmo ano de Alberto Nepomuceno, 1864, e desaparecido em 1949. Essa questão tange o problemia dos autores que, tendo iniciado sua produção sob a égide romântica, evoluíram em direção ao modernismo, buscando uma atualização da linguagem musical.

Compositores nascidos após 1884 e que eventualmente tenham produzido música de câmara romântica também foram excluídos do nosso trabalho, pois tal grupo de obras demandaria uma análise musical interna com a finalidade de separar a produção dos autores em "fases", tarefa que exorbita as propostas e possibilidades do presente trabalho, vinculado a uma conceituação predominantemente histórica, que se respalda numa delimitação cronológica e não na análise das obras, proposta esta para um trabalho futuro.

O levantamento da produção camerística brasileira do período romântico foi feito sobre fontes bibliográficas, com a consulta a cerca de trinta obras; e sobre fontes primárias, consultando-se doze arquivos nacionais: a Biblioteca Nacional do Rio de Janeiro, a Biblio- 
teca da Escola de Música da Universidade Federal do Rio de Janeiro (antiga Escola Nacional de Música), o Arquivo Nacional do Rio de Janeiro, o Conservatório Dramático e Musical de São Paulo, o Centro Cultural São Paulo, o Instituto de Estudos Brasileiros da Universidade de São Paulo, o Museu Carlos Gomes de Campinas, a Discoteca Pública Natho Hehn de Porto Alegre, o Museu VillaLobos do Rio de Janeiro, o Museu da Imagem e do Som do Rio de Janeiro, a Coleção Particular de Sérgio Nepomuceno Alvim Corrêa (neto de Alberto Nepomuceno) e o acervo de manuscritos musicais do Arquivo Municipal de Salvador, Bahia.

A necessidade de realização de um catálogo das obras em questão foi formulada não apenas para se obter uma ampliação numérica do repertório conhecido, mas também pela necessidade de reunir e compatibilizar dados que se apresentam esparsos na documentação não-musical e na bibliografia específica, com a realidade dos documentos musicais existentes nos arquivos. $\mathrm{O}$ trabatho de catalogação procurou definir os elementos essenciais para identificação da obra, a localização de seus exemplares, manuscritos ou editados, e implicou certa abordagem histórico-reflexiva, fornecendo dados relativos à divulgação da obra por meio de edições, audições de época, crítica musical e registro fonográfico.

$\mathrm{O}$ número crescente de verbetes que a pesquisa suscitou superou nossas expectativas. Iniciamos o projeto com cerca de uma centena de obras de uma dezena de autores. Atualmente, após a pesquisa nos principais arquivos e fontes disponíveis até o momento, chegamos a quase quatrocentas obras de cerca de setenta autores. Esse aumento acentuado de obras demandou uma série de pesquisas paralelas e exigiu um constante reequacionamento dos parâmetros adotados inicialmente. Nossa preocupação maior foi procurar aprofundar o conhecimento atual do romantismo musical brasileiro, não apenas quantitativamente mas, na medida em que a natureza das informações do catálogo permite, também conceitualmente, já que estaríamos abordando um gênero musical histórica e socialmente significativo. Após o levantamento das fontes, procuramos dar um tratamento crítico-reflexivo, tentando uma 
interpretação da documentação tanto quanto possivel aprofundada do período romântico brasileiro através do prisma da produção camerística.

\section{A música de câmara no Brasill}

Até meados do século XIX, o Brasil teve uma atividade camerística apenas embrionária. Francisco Curt Lange, em seu Informe Prelimiar (1946), comunica ter ençontrado, de Minas Gerais do século XVIII, cópias manuscritas dos quartetos de Haydn, Pleyel e quintetos de Boccherini. Conforme o Catálogo do Acervo de Manuscritos Musicais do Museu da Inconfidência de Ouro Preto, realizado por Régis Duprat e Carlos Alberto Baltazar (no prelo), as obras mencionadas são o Quarteto de cordas op. 3 de Haydn (cópia de 1794), seis Quintetos de cordas (cópia de 1792) e um Trio de cordas (cópia de c. 1850) de Boccherini, e os Quartetos de cordas n. ${ }^{\circ} 19,20$ e 21 (cópia anterior a 1824) de Pleyel.

A música de câmara se implantou efetivamente no Brasil quando já havia se convertido em concerto público na Europa e, como ali, seu desenvolvimento esteve vinculado às sociedades musicais que eram, na maior parte das vezes, fomentadas pela burguesia emergente. O repertório camerístico figura nos concertos de diversas sociedades musicais, como o o Clube Mozart (1867-89) e o Clube Beethoven (1882-89) do Rio de Janeiro, o Clube Haydn (1883-91) de São Paulo e a Sociedade dos Concertos Clássicos (1883-89) do Rio de Janeiro. Algumas dessas sociedades mantinham um conjunto de câmara permanente, como o quarteto do Clube Beethoven, formado por Vincenzo Cernicchiaro (violino I), Kinsman Benjamin (violino II), L. Gravenstein (viola) e João Cerrone (violoncelo), e que atuou de 1883 a 1887; o quarteto da Sociedade de Concertos Clássicos, formado por Felice Bernardinelli (violino II), Luigi Gravenstein (viola) e Giovanni Cerroni (violoncelo); o quarteto do Clube Haydn, formado por José Pedro Santana Gomes (violino I), Charles Hildebrant e G. Fuchs (violino II), Francisco Regis (viola), H. Stupakoff (violoncelo) e Antônio 
Leal Júnior (contrabaixo), para a execução dos quintetos. Também tivemos, em São Paulo, a Sociedade do Quarteto Paulistano, atuante entre 1883 e 1886, composta por Giulio Bastiani (violino I), A. Pasquale (violino II), A. Martini (viola) e Guido Rochi (violoncelo).

Na virada do século, surgiram conjuntos camerísticos estáveis, como o Quarteto Tatti, do Rio de Janeiro (já atuante por volta de 1900), formado por Ricardo Tatti (violino I), Humberto Milano (violino II), Ernesto Ronchini (viola) e Maximiliano Benno Niederberger (violoncelo); o Trio Barrozo-Milano-Gomes do Rio de Janeiro (já existia por volta de 1900), formado pelo pianista Barrozo Neto, pelo violinista Humberto Milano e pelo violoncelista Alfredo Gomes; a Sociedade Pizzicato (atuante em São Paulo entre 1905 e 1907), com um quarteto de cordas formado por Giulio Bastiani, Guido Rochi, Guido Arcolani, Cicala e Lazzarini; o Quarteto Bastiani (atuante entre 1913 e 1914), composto por Giulio Bastiani (violino I), Luís Oliani (violino II), Guido Arcolani (viola), Guido Rochi (violoncelo) e, quando quinteto, Aldo Peracchi (contrabaixo); os Concertos de Música de Câmara, associação fundada em 1912 no Rio de Janeiro por Francisco Chiafitelli, com a colaboração da pianista Sílvia Figueiredo e do violoncelista $\mathrm{H}$. Hesse de Mello.

Tal modalidade alcançou também outros centros, como Belém do Pará, onde Menelau Campos organizou um quarteto de cordas entre 1900 e 1903 e Paulino Chaves fundou e liderou o Quarteto Beethoven em 1914. Em 1915, um grupo de admiradores, liderado por Luciano Gallet, funda no Rio de Janeiro a Sociedade Glauco Velasquez, com a finalidade de divulgar e imprimir a obra inédita do patrono. Tal sociedade realizou seis concertos e imprimiu algumas composições, vindo a dissolver-se em 1918. Temos conhecimento da existência, no ano de 1919, do Septeto Arte e Beneficência, do Pará.

Esses clubes musicais constituíram-se em verdadeiros agentes divulgadores da música de câmara produzida por compositores brasileiros e por estrangeiros. As informações que obtivemos a res- 
peito das execuções de obras de câmara do período romântico brasileiro mostram que tais sociedades realizaram diversas primeiras audições: a Sonata para violino e piano em Lá Maior de Leopoldo Miguez, executada pelo próprio autor ao violino e Artur Napoleão ao piano, no clube Beethoven do Rio de Janeiro a 12 de julho de 1886; a Prece para violoncelo e piano em Fá menor de Alberto Nepomuceno, executada pelo próprio autor ao piano e Frederico Nascimento ao violoncelo, no Clube Iracema de Fortaleza a 25 de abril de 1888; o Trio para piano e cordas, em Fát menor de Alberto Nepomuceno, executado pelo Trio Barrozo Neto, Nicolino Milano e Alfredo Gomes no Salão do Jornal do Comércio do Rio de Janeiro a 31 de agosto de 1916; o Trio para piano e cordas em Si menor op. 45 de Henrique Oswald, pelo Trio Barrozo-MilanoGomes em 1916; e o Quarteto de cordas n. ${ }^{\circ} 1$ em Si menor de Alberto Nepomuceno, executado pelo Quarteto Chiafitelli no Instituto Nacional de Música do Rio de Janeiro a 18 de maio de 1933.

As mais antigas composições de câmara de autor brasileiro são o Quarteto (s.d.) do padre José Joaquim Pereira da Veiga (Meia Ponte, atual Pirenópolis, GO, 13/5/1772 - id. 11/12/1840), citado na EMB, 1977, e o Quarteto de Damião Barbosa de Araújo (Itaparica... 1856), citado por L.H.C. Azevedo (1956, p.24), dedicado ao ministro Antônio de Araújo. O autor goiano tem a data de falecimento mais remota em relação aos demais compositores incluídos em nosso Catálogo, sendo sua obra, portanto, anterior a 1840. O ministro ao qual Damião Barbosa de Araújo dedicou o seu quarteto desempenhou tal função entre os anos de 1814 e 1817, época provável da composição dessa obra. A. EMB, 1977, cita, ainda, um Quarteto obrigado sobre motivos de D. Juan, de Mozart, de autoria de Manuel José Gomes, datado de 1851, um Quarteto para violinos e flauta (s.d.) do padre Francisco Inácio da Luz (Meia Ponte, atual Pirenópolis, GO, $2 /$ 3/1821- id. 27/8/1878) e outra obra de câmara intitulada Petites mouches, de autoria de Luísa Leonardo, datada de 1871. Não localizamos os manuscritos de nenhuma das composições mencionadas acima. A mais antiga composição do gênero, cujo 
manuscrito foi localizado em nossa pesquisa, é $A$ Saloia, variações para flauta com dois violinos, viola e violoncelo, assinada apenas por um "Sr. Araújo" e datada de "Bahia 28 de Setbro. de 1851 "; seu manuscrito autógrafo encontra-se na BNRJ.

Podemos considerar que a produção camerística brasileira se torna expressiva a partir da década de 1880. Antes disso teríamos tido uma produção irregular, com apenas cinco obras entre as décadas de 1810 e 1870 . Já na década de 1880, contamos vinte e duas obras de dez autores: Júlio Reis, José Pedro Santana Gomes, Alexandre Levy, Leopoldo Miguez, Henrique Oswald, Alberto Nepomuceno, Artur Napoleão, José Leandro Martins Filgueiras, Carlos Mesquita e Vincenzo Cernicchiaro. Da década de 1890 computamos quarenta e três obras de dezesseis autores e da primeira década deste século, oitenta e cinco obras de dezessete autores; cinqüenta e uma obras de treze autores, compostas na década de 1910; e dezoito obras na década de 1920. Chamamos a atenção para o fato de que todos esses números devem ser tomados com precaução, pois dispomos da data de composição ou edição de duzentas e cinqüenta e oito obras, o que representa cerca de $65 \%$ do total de obras catalogadas. E cento e trinta e três obras não têm data definida. Todas as ilações aqui expostas são, portanto, relativas. $\mathrm{O}$ número decrescente de obras camerísticas produzidas nos anos que antecedem e sucedem a Semana de 1922 refere-se, obviamente, apenas às obras consideradas românticas, não significando, portanto, que a produção camerística brasileira como um todo tenha decaído.

Do conjunto de cerca de setenta compositores que reunimos em nossa pesquisa, uma dezena é de estrangeiros radicados no Brasil - tratando-se de figuras significativas para a vida musical brasileira do período. Dos autores brasileiros, dezesseis são do estado do Rio de Janeiro e quinze de São Paulo, já perfazendo mais de 60\% do total. Demais estados têm parcela menor, dos quais destacamse Maranhão com cinco compositores, Pará com quatro e Minas Gerais e Bahia com três cada um. Essa realidade expressa, eviden- 
temente, o estado atual da documentação armazenada nos arquivos consultados e retrata a realidade historiográfica brasileira.

Todos os expoentes do romantismo abordaram o gênero camerístico: Antônio Carlos Gomes, Alberto Nepomuceno, Henrique Oswald, Glauco Velasquez, Leopoldo Miguez, Francisco Braga e Alexandre Levy. Dado o número elevado de obras arroladas, aventamos a possibilidade de a produção camerística vir a valorizar a projeção de compositores considerados de menor importância. Os compositores que mais escreveram música de câmara foram Glauco Velasquez, com quarenta e quatro títulos; Francisco Braga, com trinta e um títulos; Henrique Oswald, com trinta títulos; Murilo Furtado, com vinte e um títulos; Menelau Campos, com vinte títulos; Santana Gomes, com dezenove títulos e Barrozo Neto, com quinze títulos. Destacamos, entre os demais compositores, João Gomes Araújo, com onze títulos; Alberto Nepomuceno, com dez títulos; João Gomes Júnior, com nove títulos; Leopoldo Miguez, com oito títulos; e Alexandre Levy, com sete títulos.

\section{Gêneros musicais}

O estudo dos gêneros musicais cultivados pelos compositores constitui aspecto importante para um entendimento de seus ideais estéticos. Se o período clássico acreditava em modelos formais que pudessem proporcionar equilíbrio e unidade ao discurso musical, o romântico buscava novas possibilidades de criação, utilizando freqüentemente sintaxe curta. Considerando que o romantismo europeu valorizou os gêneros de morfologia curta, procuramos avaliar a freqüência dos gêneros de morfologia longa e curta, das pequenas e grandes formas na produção camerística.

Os gêneros musicais cultivados no repertório pesquisado conferiram superioridade numérica às peças de morfologia curta, tanto a música brilhante de entretenimento, as danças, como as peças líricas. Estas últimas, definidas por Friedrich Blume (1970, p. 1479) como pequenas obras de arte, que podem ser consideradas entre as mais preciosas e características de toda a música romântica e 
uma das melhores realizações do século, foram produzidas em abundância pelos compositores europeus. Também foram amplamente cultivadas pelos compositores brasileiros, não apenas na música para piano solo, mas também na música de câmara. Constituem cerca de metade de toda a produção camerística catalogada até o presente momento e, entre elas, predominam o romance e a berceuse. As danças representam cerca de $15 \%$, predominando aí o mimeto e valsa; e a música brilhante, cerca de $5 \%$, sobretudo fantasias e caprichos.

A música brilhante, de entretenimento, testemunha um alto padrão de gosto cultural, que acompanhou o interesse generalizado pela destreza digital. $\mathrm{O}$ interesse permaneceu inteiramente no brilhantismo da técnica e na profundidade da expressão emocional. A este gênero pertencem as composições virtuosísticas como a fantasia de concerto, a fantasia de bravura, o étude romântico, o concert-étude, caprice e similares. Esse tipo de peça brilhante de bravura cresceu dentro de uma extensiva literatura e foi freqüentemente amalgamado com a peça lírica para piano. Entretanto, decaiu, vítima de efeitos especiais, finalmente levado à música de salão e à corrupção do gênero (cf. F. Blume, 1970, p. 148-9).

A música brilhante de entretenimento se expressa na produção camerística brasileira em pequena proporção, porém, nas diversas modalidades: Capricho, Étude de concert, Fantasia, Moto Perpétuo, Variaçôes sobre tema original, Variações brilhantes, Solo concertante.

As danças, cada vez mais, tomaram lugar na música séria, desde os clássicos até os românticos, tanto em formas simples ou estilizadas (minueto, danças germânicas, schottisch, valsa, polca, mazurca, galope, cancan, polonaise, czardas, danças húngaras, eslavas) como suas formas e ritmos explorados em movimentos de quartetos, quintetos, trios e sonatas. A circunspeção em relação às danças observada no período clássico não perdurou entre os compositores românticos (cf. Blume, 1970, p. 146). Esse gênero tem presença significativa no repertório camerístico brasileiro sob uma 
variedade: Gavota, Bolero, Habanera, Galope, Giga, Mazurca, Polca, Saltarello, Sapateado, dança espanhola, Sarabanda, Tango caprichoso, Tarantela, Valsa, Zingaresca. A música de salão foi expressa literalmente nas Peças de salão de Vincenzo Cernicchiaro.

A peça lírica, uma especialidade do século XIX (cf. Blume, 1970, p. 146), aparece entre os compositores europeus sob as mais variadas denominações: bagatelle, impromptu, intermezzo, élégie, éclogue, humoresque, nocturne, moment musical, barcarole, rhapsody, ballade, dithyrambe, "Song without words" e outras. Contingente bastante expressivo da produção camerística romântica brasileira apresenta títulos abstratos juntamente com títulos sugestivos ou pictóricos. Os primeiros estão exemplificados nos Andante, Adagio sostemuto, Canção, Ária, Madrigal, Prelúdio, Scherzo e Suite.

Entretanto, a maior parte dessas peças líricas recebe denominações pertencentes ao vocabulário especificamente romântico como, por exemplo, Berceuse, Bluette, Barcarolle, Élégie, Feuilles d'album, Impromptu, Intermezzo, Idylle, Nocturne, Rêverie, Romance, Romance sem palavras e Sérénade.

Observamos que, às vezes, essas peças líricas traduzem títulos sugestivos: Romance "Pourquoi?", de Kinsman Benjamin; Rêverie "Per far sognare", de Glauco Velasquez; Serenata "Silenzio", de Araújo Viana; Intermezzo "Ronde des nymphes", de Júlio Reis; Berceuse "Mater dolorosa", de Nicolino Milano; Berceuse orientale, de Murilo Furtado; Chant d'automne, de Francisco Braga; Extase, de Barrozo Neto, Glauco Velasquez; Desio, de Glauco Velasquez; Meditação "Al chiaro di lune", de Antônio Carlos Gomes; Meditação "Une Larme", de Brazilio Itiberê da Cunha; Malinconía, de Menelau Campos; Canto Celeste e Nostalgia, de Elpídio Pereira; Canto d'amore, de Glauco Velasquez; Canto elegiaco, de Henrique Oswald; Mistero, de Glauco Velasquez; Frammento del sogno d'amore, de Glauco Velasquez; Il Lamento degl'orfanelli, de Santana Gomes; Scène à la mer, de Alexandre Levy; Pensiero de allucina (Obsessão), de Glauco Velasquez; Pagine descrittive, de Glauco Velasquez. 
Esse gosto pelos títulos sugestivos alcançou também obras de morfologia longa, como a Sonata "Delirio" de Glauco Velasquez; a Fantasia "Pianto d'amore" de Murilo Furtado; e muitos outros.

Alguns desses títulos demonstram certa preocupação em forjar um vocabulário mais brasileiro, senão nacionalizante: Nostalgia, Serenata "Brasileira", de Elpídio Pereira; Serenata rústica, de Bento de Albuquerque Moçurunga; Seresta "Diálogo sonoro ao luar", Impressões da roça, Sol poente, Toada, Minha terra, Visões, Cantilena mupcial, Bendengo, de Francisco Braga; Elegia "Saudade", Berceuse "Mariinha", de Inácio Manuel Cunha; Saudade, de Santana Gomes; Romance "Inocência", de Misael Domingues; Elegia "Silvia!...", de Leopoldo Miguez; Ária "Alvorada das rosas", de Júlio Reis; Faceirice, Coriscos, Canto de amor, de Barrozo Neto; Primavera, de João Gomes Araújo; Suíte Brasileira, de Menelau Campos; Tristeza, Nostalgia, Melancolia, de Glauco Velasquez; Cantiga sertaneja, de João Gomes Júnior; Devaneio, de Alberto Nepomuceno; Reminiscência, de Agnello França; Ondulações, de Homero Sá Barreto.

O conjunto de títulos Serenata espanhola, de Giulio Bastiani, Serenata napolitana, de Carlos Mesquita e Serenata "Brasileira", de Elpídio Pereira, demonstram a presença de certo sentido de nacionalidade acompanhado da tentativa de se forjar um abrasileiramento do gênero.

Esta é uma amostragem bastante significativa que, embora extensa, não esgota a diversidade de títulos dessa parcela da produção camerística brasileira.

As peças líricas e as danças deram sua particular contribuição para o cultivo da música no lar da classe média e para a educação musical. Na medida em que a música destinada ao concerto tomou um caráter virtuoso e excedeu às capacidades do diletante, a peça lírica, junto com a dança e a canção, entrou na brecha, permanecendo até o século XX como um campo favorito do amador culto e do professor de música. Se de um lado tínhamos a música brilhante de entretenimento, virtuosística, praticada por profissionais, 
de outro, estavam a peça lírica, a dança e a canção, que eram consumidas na maior parte por diletantes. Evidentemente, as obras não se encontram estancadas em tais categorias e as fronteiras que as delimitam são bastante sutis. Em alguns casos, ambas, peça lírica e música brilhante, amalgamaram-se.

Os gêneros de morfologia longa, afins à forma-sonata, representam cerca de um quinto da produção camerística do período, ou seja, cerca de oitenta títulos, e demonstram que, como entre os compositores europeus, os compositores brasileiros tiveram, nesse gênero, o campo de expressão mais íntima, propício à consolidação da técnica composicional, às experimentações e tentativas de expansão do discurso musical e de superação estéticocomposicional. Isso se verifica também numa parcela das peças líricas, de maior pretensão estética. Nesse gênero de morfologia longa temos vinte e seis quartetos de cordas, treze trios para piano, violino e violoncelo, onze sonatas para violino e piano e seis sonatas para violoncelo e piano. Formações camerísticas configuradas no romantismo, como o quarteto e o quinteto para piano e cordas, não foram abordados por compositores românticos brasileiros, com exceção de Henrique Oswald e João Gomes Araújo. Formações instrumentais maiores figuram em menor quantidade e dentre elas destaca-se o Octeto para cordas de Henrique Oswald. Os gêneros de morfologia longa continuam sendo um campo de adestramento e comprovação de sólida técnica composicional.

De vinte e seis quartetos de cordas, quatro são de Henrique Oswald, quatro de João Gomes Júnior, quatro de Menelau Campos, quatro de Alberto Nepomuceno, três de Santana Gomes, dois de Paulo Florence e um de cada um dos autores que se seguem: Glauco Velasquez, Alexandre Levy, João Gomes Araújo, Jerônimo Emiliano Sousa Queirós, Henrique Eulálio Gurjão. Acrescentamos ainda mais quatro quartetos, que supomos serem também para cordas, dos seguintes autores: padre Joaquim Pereira da Veiga, Paulino Chaves, Damião Barbosa Araújo e Ezequiel Paula Ramos Júnior.

De treze trios para piano e cordas, quatro são de Glauco Velasquez, três de Henrique Oswald, dois de Alexandre Levy, um 
de Alberto Nepomuceno, um de Francisco Braga, um de Paulo Florence e um de Homero de Sá Barreto.

De seis sonatas para violoncelo e piano, duas são de Henrique Oswald, duas de Glauco Velasquez, uma de Homero Sá Barreto e uma de Paulo Florence.

Os dois quartetos para piano e cordas são de Henrique Oswald. Apenas um trio de cordas, de Nicolino Milano, um quinteto de cordas de Antônio Carlos Gomes e um quinteto de piano e cordas de Henrique Oswald.

No período romântico, a atividade camerística se desenvolveu basicamente em dois campos: o do sarau doméstico e o da sala de concerto. O repertório da música doméstica era consumido pelos amadores ou estudantes de música e era formado por obras de morfologia curta e de execução fácil ou mediana. A maior parte dessas peças era escrita para conjunto instrumental reduzido, geralmente duos, às vezes com versão para piano solo. De quase quatrocentas obras catalogadas, localizamos trinta e três peças com versão para piano solo, das quais nem sempre foi possível determinar se se tratava de obra para piano solo arranjada para conjunto de câmara ou de obra para conjunto de câmara reduzida para piano solo. De qualquer maneira, esse número relativamente pequeno demonstra que o idioma instrumental cameristico se desenvolvia com autonomia. Não se trata de obras pianísticas transcritas para agrupamento instrumental, mas de um conjunto de composições concebidas cameristicamente. Esse conjunto de obras destinadas à prática doméstica subdivide-se em músicas de iniciação ao repertório erudito ou culto, algumas inclusive com certo cunho didático, e músicas que se aproximam da música de salão, realizadas porém com uma certa pretensão de distinção. Destacamos a peça lírica, gênero propício à liberdade formal, que procurou uma alternativa à forma-sonata explorando a morfologia curta.

Embora as peças características figurassem nos programas de concertos públicos, o repertório destinado a executantes profissionais e à sala de concerto abordava freqüentemente gêneros musicais de morfologia longa ou obras de maior pretensão artística. 
Nessa categoria, a prática do arranjo também esteve presente. É possivel que, muitas vezes, o compositor almejasse escrever uma composição orquestral, sem dispor de elementos instrumentais para a execução. Acabava por se adequar ao instrumental disponível, realizando composição para um conjunto reduzido. Em geral, essas obras não exploram o idioma instrumental tạo sistematicamente e, inclusive, temos exemplos em que o compositor realizou posteriormente a versão orquestral, tão logo a possibilidade de execução se tenha viabilizado, como é o caso do Románce e da Tarantela de Alberto Nepomuceno para violoncelo e piano, compostos respectivamente em 1889 e 1899 e posteriormente orquestrados pelo autor para serem executados. Da mesma forma, obras já realizadas para orquestra recebiam versões para conjunto de câmara, a fim de viabilizar maior freqüência da sua execução; é o caso do Minueto da Sinforia n. ${ }^{\circ} 1$ de Menelau Campos, que possui uma versão para quarteto de cordas do próprio autor; e a Sinfonia n. 5 de João Gomes Araújo, com uma versão do próprio autor para quinteto de piano e cordas.

Essa prática de o próprio compositor realizar arranjos de suas obras foi muito comum também entre os europeus. Beethoven transcreveu seu Concerto para violino, para piano e orquestra; e a Sinfonia n. ${ }^{\circ}$, para um trio piano e cordas; são exemplos, também, as várias versões de Brahms do Quinteto para piano e cordas e do Concerlo para piano n. ${ }^{\circ} 1$. Os arranjos popularizam as obras-primas e as inumeráveis transcrições levaram o repertório orquestral e camerístico para dentro das casas dos instrumentistas domésticos. Além dessa dimensão pragmática das transcrições, a natureza dos arranjos, durante o século XIX, foi largamente determinada pelo novo interesse na cor instrumental em si mesma, que trouxe consigo o conceito da criação do compositor como uma entidade inviolável (M. Boyd, 1980).

A parcela mais nobre da produção camerística brasileira em foco é a das obras concebidas para conjunto instrumental específi$\mathrm{co}$, nas quais o compositor procura explorar o idioma instrumental para o qual a obra foi concebida, não havendo, portanto, possibili- 
dade de versões instrumentais que empobreceriam ou desvirtuariam a idéia musical original. Os compositores tiveram, nesse gênero, o campo de expressão mais íntima, propício, inclusive, às experimentações e tentativas de expansão e superação. De maneira geral, todas as obras de morfologia longa de Henrique Oswald se enquadram nessa categoria, sobretudo a Sonata para violino e piano op. 36; a Sonata para violoncelo e piano op. 21 e a SonataFantasia para piano e violoncelo op. 44; os Trios op. 28 e op. 45; o Piccolo Quarteto op. 5 e o Quarteto op. 26, àmbos para piano e cordas; os Quartetos de cordas op. 39 e 46; o Quinteto op. 18. Poderíamos considerar o mesmo em relação à Sonata para violino e piano de Leopoldo Miguez; o Trio para piano e cordas de Francisco Braga; as Sonatas para violino e piano e para violoncelo e piano, os Trios para piano e cordas e o Quartelo de cordas de Glauco Velasquez; o Trio para piano e cordas de Alberto Nepomuceno, mencionando apenas os compositores consagrados. Entre as obras menos conhecidas, destacamos a Sonata para violino e piano e a Sonata para violoncelo e piano de Paulo Florence; a Sonata para violoncelo e piano e o Trio para piano e cordas de Homero Barreto.

Mas é preciso destacar que não somente as grandes formas, como também os gêneros de morfologia curta, foram muito propícios a essa natureza de concepção musical. As numerosas composições de Glauco Velasquez com formas mais livres e intimistas, juntamente com as similares de Henrique Oswald, constituem a porção mais significativa dessa categoria. Os próprios títulos utilizados por Velasquez são bastante sugestivos e demonstram certa pretensão estética e expressiva do compositor: Desio, Mistero, Elegia, Extase, Melancolia, Nostalgia, Pensiero che allucina (Obsessão), o onomástico "Delírio" da Sonata para violino e piano, Sogno, Tristezza, Rêverie "Per far sognare", Frammento del sogno d'amore, Feuille d'album "Assim eu te amo", Berceuse, Elegia, Ondulações, Rêverie, Romance, de Homero Barreto. Tais peças curtas constituíram o campo da experimentação que distanciou a linguagem romântica dos padrões clássicos ou classicizantes e re- 
presentam a grande contribuição do romantismo em relação à morfologia musical do século XIX.

Desse conjunto de quase quatrocentas obras classificadas em nosso catálogo, cerca de cento e vinte títulos foram publicados na época - quase uma centena por editoras nacionais e quase três dezenas por editoras européias. A impressão de obras de câmara brasileira classifica-se a partir da última década do século XIX, concentrando-se, basicamente, no Rio de Janeiro. Entre 1890 e 1920, todas as casas editoras cariocas publicaram música de câmara. Os países europeus que mais editaram música de câmara brasileira foram a Itália, com onze títulos, e a França, com dez títulos. Os gêneros musicais abordados pelas edições que circularam comercialmente pertencem à prática doméstica dos saraus, sobretudo as peças líricas, peças de pequena extensão e dificuldade técnica mediana, acessivel a um instrumentista amador ou estudante, principal consumidor dessas partituras. Em geral, são obras arranjadas para um conjunto instrumental reduzido, geralmente duos, algumas com versões para piano solo. A Sonata para violino e piano em Lá maior de Leopoldo Miguez, editada em Leipzig, Alemanha, pela J. Rieter-Biedermann em meados da década de 1880, constitui uma feliz exceção. Algumas obras de maior envergadura foram editadas no Brasil somente a partir da primeira década do século atual.

A maior parte da produção camerística brasileira permanece inédita. Trabalhos musicológicos atuais realizaram cinco edições de obras de câmara do período romântico brasileiro. José Eduardo Martins, pioneiro nesse setor, realizou quatro edições críticas de obras do compositor Henrique Oswald pela Novas Metas (São Paulo) em 1982: a Sonata-Fantasia op. 44 para violoncelo e piano, a Sonata op. 21 para violoncelo e piano e a Berceuse (n. ${ }^{\circ} 3$ ) para violoncelo e piano em Ré, além do Quarteto op. 26 para piano e cordas, inédito. Por volta de 1982, foi editada a Sonata "Burrico de pau" para quinteto ou quarteto de cordas, de Carlos Gomes, pela Coomusa (Rio de Janeiro), revisada por Nélson de Macedo.

A produção camerística do período confirma o deslocamento dos ambientes de cultivo da música a partir da segunda metade do 
século XIX no Brasil, repetindo o fenômeno ocorrido na Europa um século antes. Ainda conforme Blume (1970, p. 85): "o centro de cultivo da música mais valioso e vigoroso era a casa do cidadão de classe média, onde o piano, a música de câmara e a canção, em todas as suas formas, encontraram seu lugar; onde música era feita dentro do círculo da família e dos amigos numa forma que não havia existido anteriormente; onde as crianças eram educadas em música por meio de um professor particular e não pelo corpo docente de uma escola. Aqui, em última análise, reside o verdadeiro alicerce da prática musical do período clássico-romântico: 'Hausmusik'. música feira na casa do amador".

Não devemos subestimar a importância das atividades musicais domésticas, pois elas teriam preservado e desenvolvido a música instrumental camerística do período romântico. Por outro lado, o repertório camerístico esteve presente no movimento dos concertos públicos, que se tornaram mais regulares na segunda metade do século passado.

O número elevado de obras de câmara produzidas no período em questão, assim como o de autores, sugere a existência, na época, de atividade abrangente e especialmente relevante. A força criativa dos compositores românticos brasileiros deu à música de câmara uma categoria e importância social e estética como jamais tivera o Brasil até então. Não somente a música sinfônica e a música para piano solo, mas também a música de câmara era fator de reconhecimento e prestígio do compositor Muito mais do que atender à superficialidade e trivialidade das atividades de entretenimento nas danças e peças de exibicionismo virtuosístico, esse gênero se prestou, sobretudo, à expressão estética elaborada e à busca de aprimoramento da técnica da composição. A diversidade de gêneros abordados e a qualidade sensivel de grande parte desse repertório sugerem também que, não obstante esse conjunto de obras seja desconhecido da bibliografia que até agora versou sobre o período, o seu conhecimento é de suma importância para a história da música brasileira.

No Brasil, a atividade camerística era disseminada na sociedade aristocrática desde a primeira metade do século XIX e a do- 
cumentação se torna mais rica e eloq̣üente a partir das duas últimas décadas do século, quando se dissemina para outras camadas sociais. Muito mais do que mostram os livros de história da música brasileira, essa produção contribuiu inequivocamente para a formação do nosso gosto musical e pode constituir uma das parcelas mais nobres da produção musical do nosso passado recente.

\section{Bibliografia sumária}

AZEVEDO, Luiz Heitor Corrêa de. 150 anos de Música no Brasil, 18001950. Rio de Janeiro, Josć Olympio, 1956.

BLUME, Fricdrich. Classic and Romantic Music: a Comprehensive Sarvey. New York, Norton, 1970.

BOYD. Malcolm. Arrangement. In: Grove's Dictionary of Music and Musicians, 6.a ed., Londres/New York, Macmillan, 1980.

CERNICCHIARO, Vincenzo. Storia della musica nel Brasile: dai tempi coloniali sin ai nostrigiorni. 1549-1925. Milão, Fratelli Riccione, 1926.

DUPRAT, Régis \& BALTAZAR, Carlos Alberto. Acervo de manuscritos musicais: coleção F. C. Lange: compositores não-mineiros dos séculos XVIII e $X I X$, v. II (no prelo).

LANGE, Francisco Curt. Um Informe Preliminar. Boletim Latino-Americano de Música, v. 10. Montevideo, 1946.

PEQUENO, Mercedes Reis. Impressão Musical no Brasil. In: Enciclopédia da Música Brasileira. São Paulo, Art, 1977.

SALIBA, Elias Tomé. As Utopias Românticas. São Paulo, Brasiliense, 1991.

SANTOS, Isa Queirós. Origem e evolução da música em Portugal e suas influências no Brasil. Rio de Janeiro, Comissão Brasileira dos Centenários de Portugal, Imprensa Nacional, 1943.

Maria Alice Volpe é musicóloga. 